\title{
THE IMPACT OF SURFACE WAVE ON THE SEDIMENT EROSION AND DEPOSITION NEAR THE WELLOW RIVER MOUTH, CHINA
}

\author{
WANG, Z. F. ${ }^{1}-$ CAO, X. D. ${ }^{1}-$ LI, Q. J. ${ }^{2 *}-$ LIU, Y. L. ${ }^{2}$ \\ ${ }^{I}$ Shandong Province Key Laboratory of Ocean Engineering, Ocean University of China \\ Qingdao 266100, China \\ ${ }^{2}$ Yantai Oceanic Environmental Monitoring Central Station of State Oceanic Administration \\ Yantai 264006, China \\ *Corresponding author \\ e-mail: lqjwainxl@126.com
}

(Received 19 $9^{\text {th }}$ Jun 2019; accepted $16^{\text {th }}$ Oct 2019)

\begin{abstract}
In this paper, the numerical simulation of sediment erosion and siltation near the Yellow River estuary is carried out by using wave, tidal current and sediment coupling model. A fine triangular mesh is used in the pattern to improve the spatial resolution of numerical calculations. Comparing the measured water depth data with the simulation results, the result shows that the simulation results are in good agreement with the actual situation. In order to analyze the influence of waves on sediment erosion and siltation, the paper carried out wave influence experiments under four conditions: no wind, north wind, easterly wind and south wind. The experimental results show that the wave has a great influence on the erosion and siltation of the seabed in the study sea area. Under the northward wave condition, an erosion zone is distributed in the SE-NW direction, and the maximum erosion thickness is about $1.9 \mathrm{~m}$. Under the eastward wave condition, the erosion zone is north-south. The maximum scouring thickness is about $1.7 \mathrm{~m}$; the scouring and silting effect under the southward wave condition is relatively weak.
\end{abstract}

Keywords: sediment movement, wind wave, tidal current, numerical simulation

\section{Introduction}

The large amount of sediment brought by the Yellow River into the sea has changed the trend of the shoreline of the Yellow River estuary, affected the spatial and temporal distribution of the seabed erosion and siltation in the nearby sea, and affected the protection of land and ecological resources, the exploitation of offshore oil and gas, and the construction of other marine projects. The modern Yellow River delta is formed near the estuary of the Yellow River with the characteristics of short formation time, efficient sedimentation rate and loose structure which make sediments prone to be compacted and consolidate under the geo-static stress and overburden stress. It is one of the areas most susceptible land subsidence disasters in China, bringing a series of safety hazards to production and living (Liu et al., 2018).

$\mathrm{Li}$ et al. (2004) calculated the coastal erosion/accumulation rates from 1964 to 1976 using Landsat TM imagery. With the combination of historical data, field observations and satellite remotely sensed images, changes in Yellow River estuary since 1996 when were studied by Fan et al. (2005), mainly including water and sediment discharge from the river, tides, tidal currents, suspended sediment diffusion, coastline changes and seabed development. Liu et al. (2011) analyzed the temporal changes of water discharge and sediment load of the Yellow River into the sea based on hydrological data observed at Lijin gauging station from 1950 to 2008. Huang et al. (2018) investigated the distribution of 
estuarine salinity and suspended sediment by a three dimensional with numerical simulation under different flow rates. Wang et al. (2019) demonstrated that the shape and length of the Yellow River Delta coastline has changed dramatically since 1976 using the general high-tide line method, which combines remote sensing and geographic information system technology, using multi-spectral scanner, thematic mapper, and enhanced thematic mapper plus images from 1976 to 2014. Yang et al. (2017) investigated water and sediment changes by using coastline and suspended sediment concentration methods, indicate the inter-annual and intra-annual variations of the sediment concentration from 1986 to 2013.

Waves have a vitally important effect on erosion and siltation of shore beach. With the rise of coastal engineering, foreign scholars began to study the sediment movement under the action of waves, and obtained some achievements. Putting forward a variety of sediment starting formulas are mostly limited to the coarser particles of non-cohesive sediment. Because of the complexity of wave motion, the lack of understanding of the oscillating boundary layer flow caused by surface waves and the turbulent mixing mechanism inside the water body, coupled with the randomness of the sediment movement itself, brings a lot of difficulties on theoretical research about sediment movement under wave action. Xu (2003) established a multiple regression equation between the sediment flux to the sea and the influencing factors to estimate the change in the sediment flux to the sea when the influencing variables are further changed. Wang et al. (2005) use a two-dimension numerical model to reveal the tidal and wave dynamics in 2012, and conducts comparative analysis of the changes from 1996 to 2012. Kong et al. (2009) established a numerical model with the application of environmental fluid dynamics code to the Yellow River Delta. The simulation indicates that most of the sediment deposited just out of the Mouth which makes the mouth move forward into the sea $2.5 \mathrm{~km}$ per year. Zhan (2017) developed the novel cubic model, which used the ratio of a near-infrared band $(740-900 \mathrm{~nm})$ to a visible band (400-600 nm) as factors, for the retrieval of SSSC from Yellow River Estuary. Wang et al. (2019) used a three dimensional current-wave-sediment coupled model to examine the seasonal suspended sediment transport. Yao et al. (2018) developed a new multifractional, depth-averaged sediment transport module and embedded into a morph dynamic model for a sand-silt mixed shallow water environment. Comparisons with measurements over two successive tidal cycles indicate that the present model produces very good results on short-time scales.

Due to the complex natural environment, it is a difficult problem to simulate calculation of the sediment erosion and deposition in the sea area of the Yellow River estuary. It is of great significance and practical value to improve the accuracy and precision of sediment numerical simulation by using effective mode. The aim of this paper is to study the impact of surface wave on the sediment erosion and deposition near the Yellow River Mouth by numerical simulation method. The paper is devised into 5 sections. The section 2 is numerical simulation. The section 3 studies the tidal current characteristics and the impact of surface waves is analyzed in section 4. Finally, the conclusion is given in the section 5.

\section{Materials and Method}

\section{Measurement data}

Research area is near the Yellow River estuary, China, $37.5-38^{\circ} \mathrm{N}, 118.8-119.6^{\circ} \mathrm{E}$. The position of the stations is shown in Figure 1.

The measured data of tidal level is selected from May 9 to 13, 2004. The measured data of tidal current is taken from May 5 to 6 . And the measured data of sediment 
concentration is taken from May 1 to 2 . Because the various elements are measured separately and the measurement time is dispersed, only the current trend is carried out the measurement of tidal current, tidal level and sediment concentration.

The data of tidal level is measured by RBR in tidal level station, and the data is recorded every $10 \mathrm{~min}$. Tidal currents are measured every 1 hour. The current direction is measured in true north position. The current level of each vertical line is determined by the water depth. The three-point is adopted when the vertical depth is less than $5.0 \mathrm{~m}$ that is, the surface layer, the $0.6 \mathrm{H}$ layer and the bottom layer are observed. The six-point is adopted when the vertical depth is greater than $5.0 \mathrm{~m}$ that is the surface layer, $0.2 \mathrm{H}$ layer, $0.4 \mathrm{H}$ layer, $0.6 \mathrm{H}$ layer, $0.8 \mathrm{H}$ layer and the bottom layer are observed.

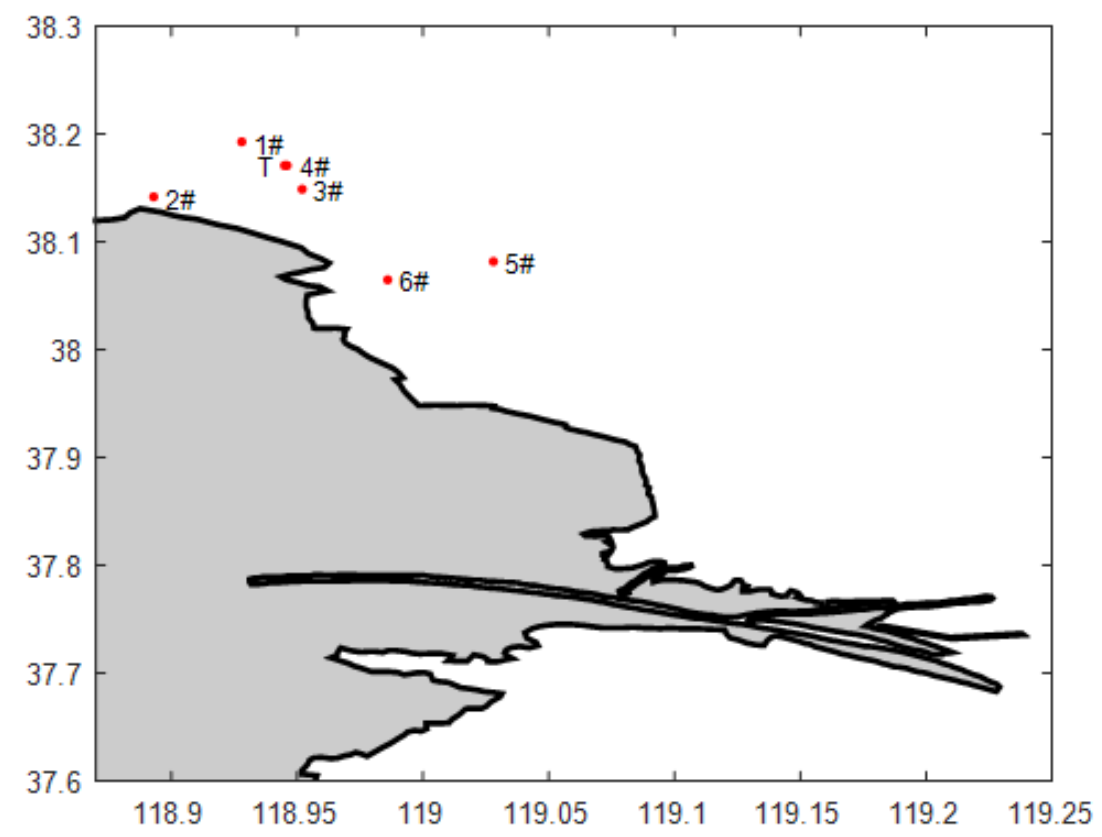

Figure 1. The Locations of observation stations

The specific levels are divided as follows:

- Surface layer: $0.5 \sim 1.0 \mathrm{~m}$ below the sea surface;

- $0.2 \mathrm{H}: 0.2 \times \mathrm{H}$ below the sea surface;

- $0.4 \mathrm{H}: 0.4 \times \mathrm{H}$ below the sea surface;

- $0.6 \mathrm{H}: 0.6 \times \mathrm{H}$ below the sea surface;

- $0.8 \mathrm{H}: 0.8 \times \mathrm{H}$ below the sea surface;

The bottom layer: $0.5 \sim 1.0$ meter above the sea floor. Where $\mathrm{H}$ is the depth of the vertical water depth during observation, in meters.

Water depth is recorded and water sample are collected for suspended sediment analysis layer by layer when measuring the current.

According to the stratified sediment concentration measured by indoor cup-dry method and weighted by stratified current rate, the average vertical sediment concentration was calculated according to the following formula:

$$
\bar{\rho}=\frac{\rho_{\text {surface }} \cdot v_{\text {surface }}+2\left(\rho_{0.2} \cdot v_{0.2}+\rho_{0.4} \cdot v_{0.4}+\rho_{0.6} \cdot v_{0.6}+\rho_{0.8} \cdot v_{0.8}\right)+\rho_{\text {bottom }} \cdot v_{\text {bottom }}}{v_{\text {surface }}+2\left(v_{0.2}+v_{0.4}+v_{0.6}+v_{0.8}\right)+v_{\text {bot tom }}}
$$




\section{Numerical Model}

Numerical simulation is an effective method to study the sediment moment and the model in this paper has been also applied and confirmed reliable by Wang et al. (2019). The hydrodynamic model is based on the two-dimensional planar incompressible Reynolds average Navier-Stokes shallow water equation, in which the Boussinesq hypothesis and the hydrostatic pressure hypothesis are used, so that the tide surface can be more accurately Curves and tidal fluxes are simulated. The following two-dimensional depth-average shallow water equations can be obtained by integrating the horizontal momentum equation and the continuous equation in the range:

$$
\begin{gathered}
\frac{\partial h}{\partial t}+\frac{\partial h \bar{u}}{\partial x}+\frac{\partial h \bar{v}}{\partial y}=h S \\
\frac{\partial h \bar{u}}{\partial t}+\frac{\partial h \bar{u}^{2}}{\partial x}+\frac{\partial h \bar{v} u}{\partial y}=f \bar{v} h-g h \frac{\partial \eta}{\partial x}-\frac{h}{\rho_{0}} \frac{\partial p_{a}}{\partial x}-\frac{g h^{2}}{2 \rho_{0}} \frac{\partial \rho}{\partial x}+\frac{\tau_{s x}}{\rho_{0}}-\frac{\tau_{b x}}{\rho_{0}}- \\
\frac{1}{\rho_{0}}\left(\frac{\partial s_{x x}}{\partial x}+\frac{\partial s_{x y}}{\partial y}\right)+\frac{\partial}{\partial x}\left(h T_{x x}\right)+\frac{\partial}{\partial y}\left(h T_{x y}\right)+h u_{s} s \\
\frac{\partial h \bar{v}}{\partial t}+\frac{\partial h \bar{v}^{2}}{\partial x}+\frac{\partial h \bar{v} \bar{u}}{\partial y}= \\
f \bar{u} h-g h \frac{\partial \eta}{\partial x}-\frac{h}{\rho_{0}} \frac{\partial p_{a}}{\partial y}-\frac{g h^{2}}{2 \rho_{0}} \frac{\partial \rho}{\partial y}+\frac{\tau_{s y}}{\rho_{0}}-\frac{\tau_{b y}}{\rho_{0}}- \\
\frac{1}{\rho_{0}}\left(\frac{\partial s_{y x}}{\partial x}+\frac{\partial s_{y y}}{\partial y}\right)+\frac{\partial}{\partial x}\left(h T_{x y}\right)+\frac{\partial}{\partial y}\left(h T_{y y}\right)+h v_{s} s
\end{gathered}
$$

Among them: the first item on the left is the local item, the second and third items are the horizontal convection items, $\mathrm{t}$ is the time, $\mathrm{x}$ and $\mathrm{y}$ are the Cartesian plane coordinates, $d$ is the still water depth, $\eta$ is the water level, $h=\eta+d$ is the total water depth, and $f$ is the Coriolis parameters $\bar{u}$ and $\bar{v}$ are respectively the components of the depth average flow velocity in the $\mathrm{x}$ and $\mathrm{y}$ directions, $\mathrm{g}$ is the acceleration of gravity, $\rho$ is the water density.

The equations for sediment transport are following:

$$
\frac{\partial \bar{c}}{\partial t}+u \frac{\partial \bar{c}}{\partial x}+v \frac{\partial \bar{c}}{\partial y}=\frac{1}{h} \frac{\partial}{\partial x}\left(h D_{x} \frac{\partial \bar{c}}{\partial x}\right)+\frac{1}{h} \frac{\partial}{\partial y}\left(h D_{y} \frac{\partial \bar{c}}{\partial y}\right)+Q_{L} C_{L} \frac{1}{h}-S
$$

where ${ }^{\bar{c}}$ is the suspended sediment concentration, $D_{x}$ and $D_{y}$ are diffusion coefficient, $\mathrm{Q}_{\mathrm{L}}$ is the point source emission per unit level area, $\mathrm{C}_{\mathrm{L}}$ is point source emission concentration, $\mathrm{S}$ is the source of deposition or erosion.

The sedimentation rate could be expressed as

$$
S D=w_{s} \cdot c_{b} \cdot p_{d}
$$

where $\mathrm{w}_{\mathrm{s}}$ is the sedimentation velocity; $\mathrm{c}_{\mathrm{b}}$ is the bottom sediment concentration; $\mathrm{p}_{\mathrm{d}}$ is the settlement probability. 
In the case of limited water depth, the fluctuation velocity of water quality points can be expressed by the following formula:

$$
\begin{gathered}
u=\frac{\pi H}{T} \frac{\cosh [k(z+h)]}{\sinh k h} \cos (k x-\sigma t) \\
v=\frac{\pi H}{T} \frac{\sinh [k(z+h)]}{\sinh k h} \sin (k x-\sigma t)
\end{gathered}
$$

In the formula, $k$ is wave number, $\sigma$ is angular frequency, $t$ is time, $h$ is water depth, $L$ is wavelength, $u$ and $v$ represent horizontal and vertical velocity of fluctuating water quality points.

The equation of unbalanced transport of suspended sediment under the combined action of tidal current and wave can be expressed as follows:

$$
\frac{\partial(h S)}{\partial t}+\frac{\partial\left[h S\left(U_{c}+U_{w}\right)\right]}{\partial x}+\frac{\partial\left[h S\left(V_{c}+V_{w}\right)\right]}{\partial y}-\varepsilon_{S} h\left(\frac{\partial^{2} S}{\partial x^{2}}+\frac{\partial^{2} S}{\partial y^{2}}\right)+a w\left(S-S_{*}\right)=0 \text { (Eq.9) }
$$

where $S$ is sediment content, $S * i$ s sediment carrying capacity of current, $\varepsilon_{s}$ is sediment diffusion coefficient, $\sigma$ is recovery saturation coefficient, $w$ is sediment settling velocity.

The reciprocating sediment transport process of waves is generally reflected in a tidal current cycle (half a day or one day). Because the wave period is relatively small (usually only a few seconds, the wave height greater than 10 seconds in the sea area near the Yellow River Estuary is very rare), the tidal current cycle is relatively large. Therefore, as long as the calculated time step is much longer than the wave period (e.g. more than 200 seconds for $\mathrm{dt}$ ), the transport equation can be averaged in time. When a wave particle rotates elliptically or circularly, its average velocity in the wave period is equal to zero, and it is also zero when the time step is longer than the wave period, so only the current tide velocity is considered. The results of the above equation are as follows:

$$
\frac{\partial(h S)}{\partial t}+\frac{\partial\left(h S U_{c}\right)}{\partial x}+\frac{\partial\left(h S V_{c}\right)}{\partial y}-\varepsilon_{S} h\left(\frac{\partial^{2} S}{\partial x^{2}}+\frac{\partial^{2} S}{\partial y^{2}}\right)+a w\left(S-S_{*}\right)=0
$$

Because the imbalanced transport of suspended sediment causes the erosion and siltation of the seabed, the deformation equation can be expressed as follows:

$$
\frac{\partial(h S)}{\partial t}+\frac{\partial\left(h S U_{c}\right)}{\partial x}+\frac{\partial\left(h S V_{c}\right)}{\partial y}-\varepsilon_{S} h\left(\frac{\partial^{2} S}{\partial x^{2}}+\frac{\partial^{2} S}{\partial y^{2}}\right)+\gamma \frac{\partial \eta}{\partial t}=0
$$

Among them, $\gamma$ is the dry density of sediment deposited on the seafloor, $\eta$ is the change of the thickness of the seafloor, $h$ is the erosion and siltation.

It can be seen from the above that when calculating the sediment erosion and siltation changes in estuaries and coasts on a large time scale, the short-period wave flow field is not needed to be taken into account, and only the effect of tidal current is considered. However, it cannot be concluded that the effect of wave on erosion and siltation can be time-averaged, because the wave will affect the sediment carrying capacity of seawater. 


\section{Results}

\section{Model validation}

The Yellow River Delta locates in the Bohai Sea, which is a shallow semi-enclosed sea that exchanges with the Yellow Sea through the Bohai Strait between Shan Dong and Liao Dong Peninsulas. The topography datasets used in this paper are shown in Fig. 2. The modeling range includes the whole of the Bohai Sea (Fig. 2a). The triangular mesh is adopted with the resolution $5 \mathrm{~km}$ at the open boundary and $700 \mathrm{~m}$ at Yellow River Delta nearshore. The model domain is $117.5^{\circ} \mathrm{E}-122.5^{\circ} \mathrm{E}, 37^{\circ} \mathrm{N}-41^{\circ} \mathrm{N}$ (Fig. 2b). On the open boundary the amplitudes and phases of the four main tidal constituents $\left(\mathrm{M}_{2}, \mathrm{~S}_{2}, \mathrm{~K}_{1}\right.$, $\mathrm{O}_{1}$ ) are used as the surface elevation forcing on the open boundaries. At the lateral land boundary, a condition of no normal flux is applied to velocity.

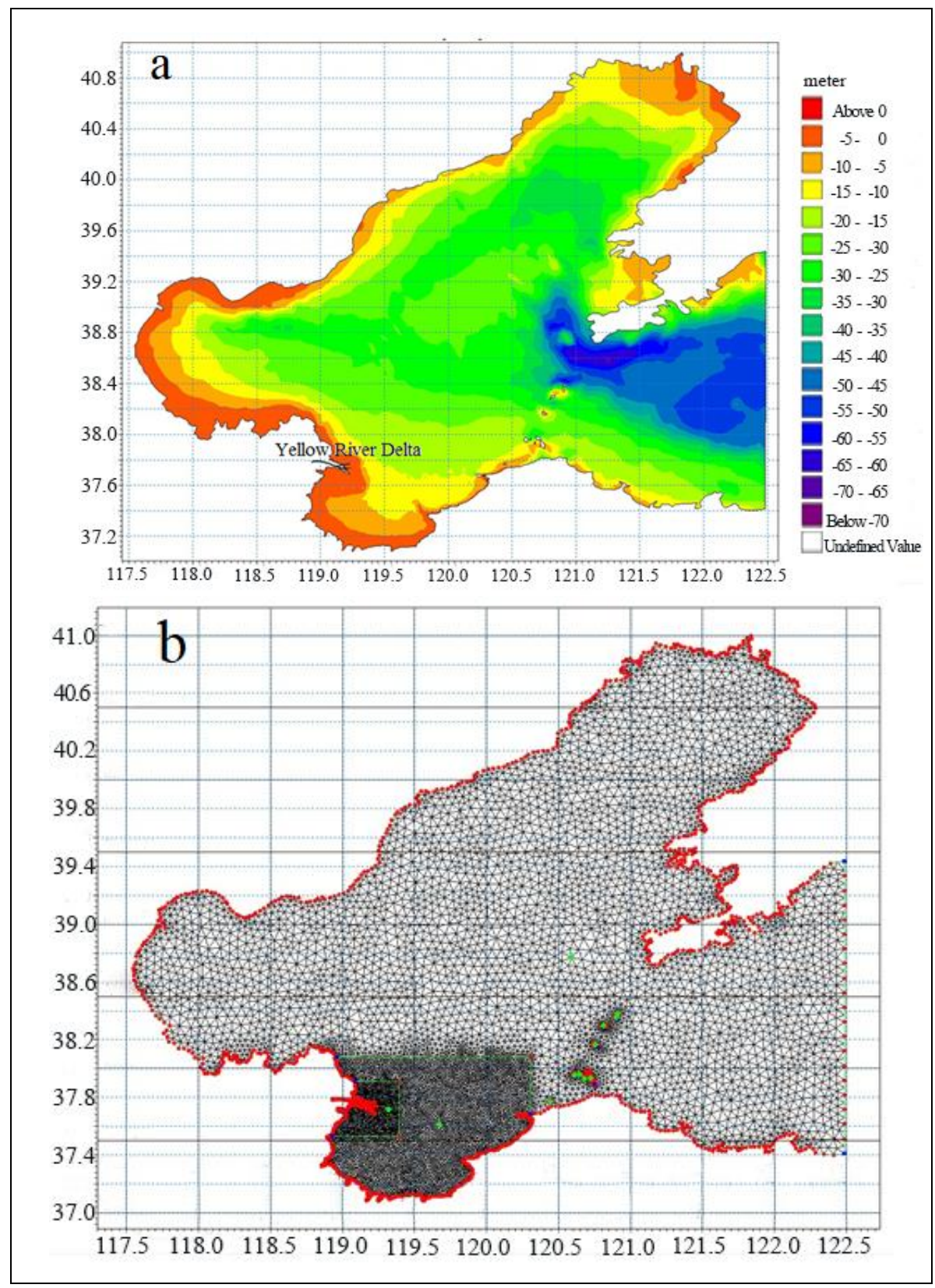

Figure 2. The topography of Bohai Sea (a) and the model grid (b) 
The measured data of tidal level, tidal current and sediment concentration are collected. The distribution of station positions is shown in Table 1. The tidal level, tidal current and sediment concentration in May 2004 were simulated and compared with the measured data. The results are shown from Figure 3 to Figure 5. The comparison shows that it is reasonable to use this model to simulate the hydrodynamic and sediment scouring in the sea near the Yellow River Mouth.

Table 1. Locations of observation stations

\begin{tabular}{c|c|c|c}
\hline No. & Longitude & Latitude & Elements \\
\hline T & $118^{\circ} 56.733^{\prime}$ & $38^{\circ} 10.233^{\prime}$ & Tidal Level \\
$1 \#$ & $118^{\circ} 55.650^{\prime}$ & $38^{\circ} 11.600^{\prime}$ & Tidal Currents \\
$2 \#$ & $118^{\circ} 53.553^{\prime}$ & $38^{\circ} 8.547^{\prime}$ & Tidal Currents \\
$3 \#$ & $118^{\circ} 57.100^{\prime}$ & $38^{\circ} 8.933^{\prime}$ & Tidal Currents \\
$4 \#$ & $118^{\circ} 56.733^{\prime}$ & $38^{\circ} 10.233^{\prime}$ & Tidal Currents \\
$5 \#$ & $119^{\circ} 01.685^{\prime}$ & $38^{\circ} 04.909^{\prime}$ & Tidal Currents and Sediment \\
$6 \#$ & $118^{\circ} 59.200^{\prime}$ & $38^{\circ} 3.920^{\prime}$ & Tidal Currents and Sediment \\
\hline
\end{tabular}

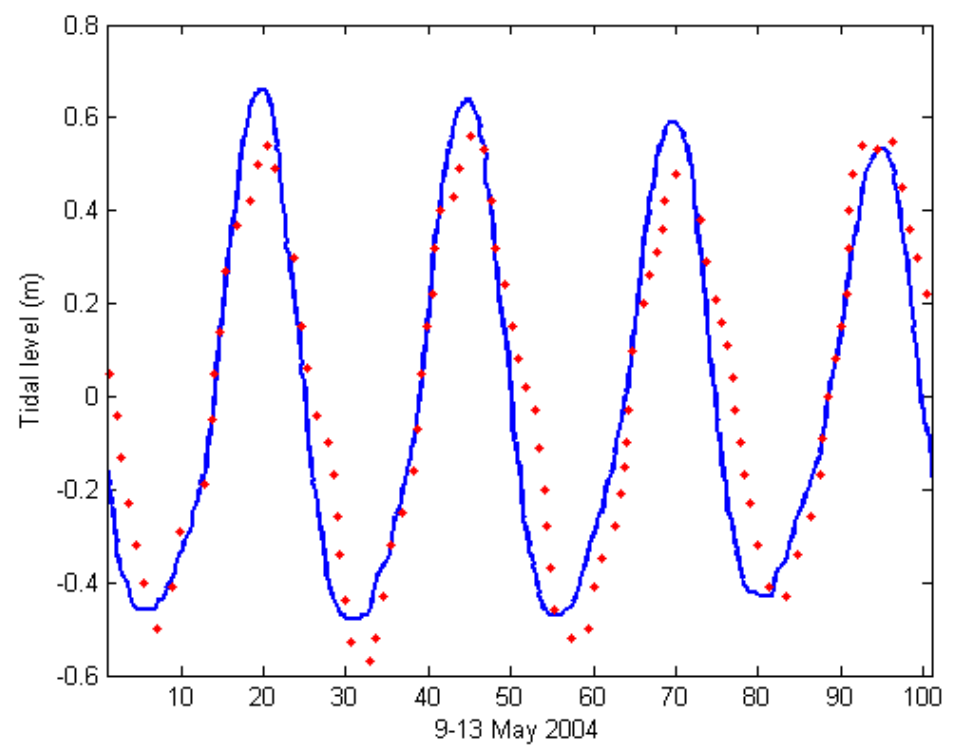

Figure 3. Comparison of observation tidal level (red dot) and simulation result (blue line)

The accuracy of the model is estimated by the average absolute error. The average absolute error is calculated as follows:

$$
A M E A N=\frac{1}{N} \sum_{i=1}^{N}\left|X_{\bmod }^{i}-X_{o b s}^{i}\right|
$$

Where $\mathrm{N}$ is the number of observing stations, $X_{\bmod }^{i}$ is the value of the mode result interpolated to the i-th station, $X_{o b s}^{i}$ is the measured value of the i-th observatory.

The average absolute error of each element of each measurement point is shown in Table 2. 

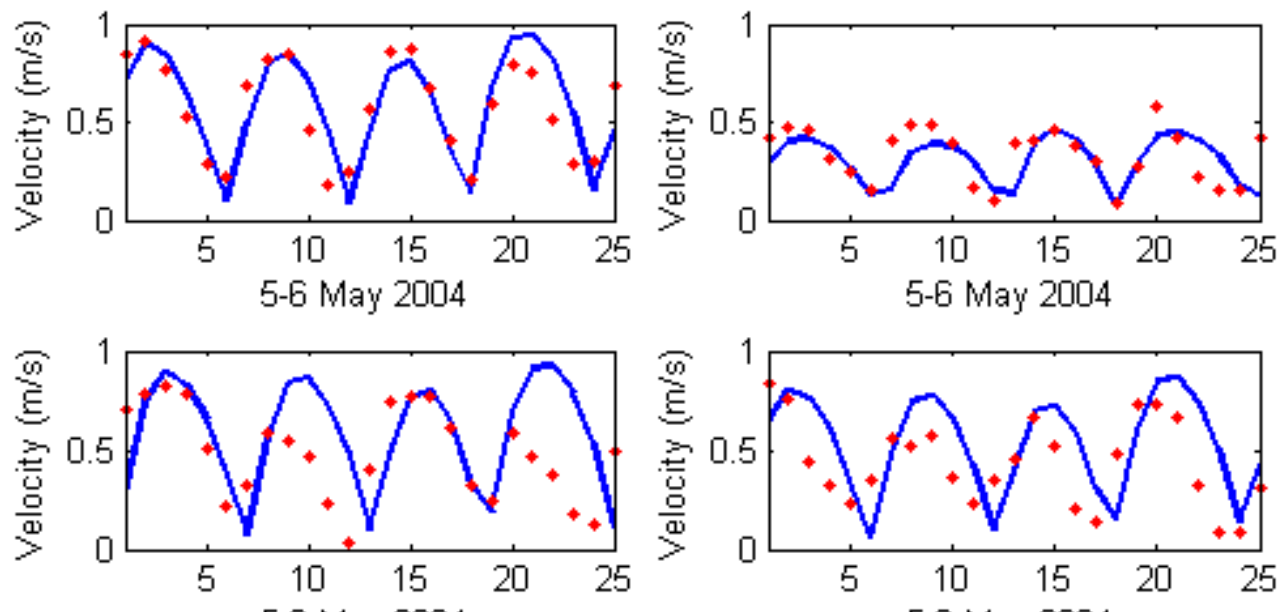

$5-6$ May 2004
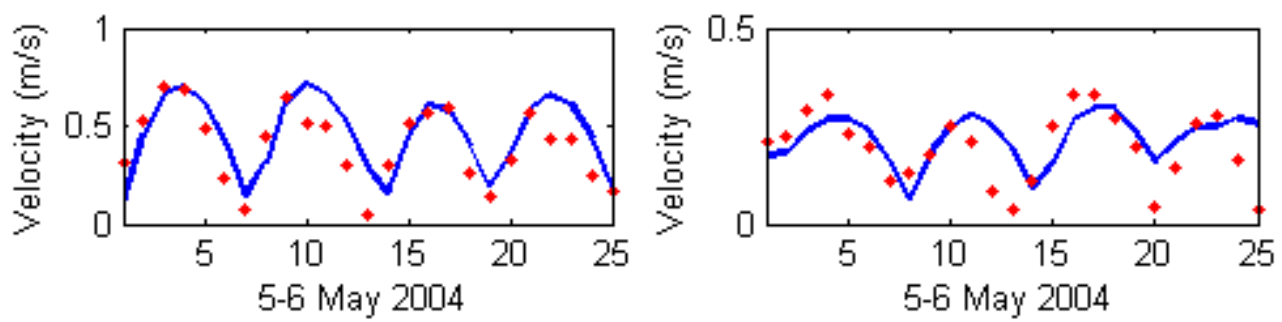

Figure 4a. Comparison of observation tidal current velocity (red dot) and simulation result (blue line)
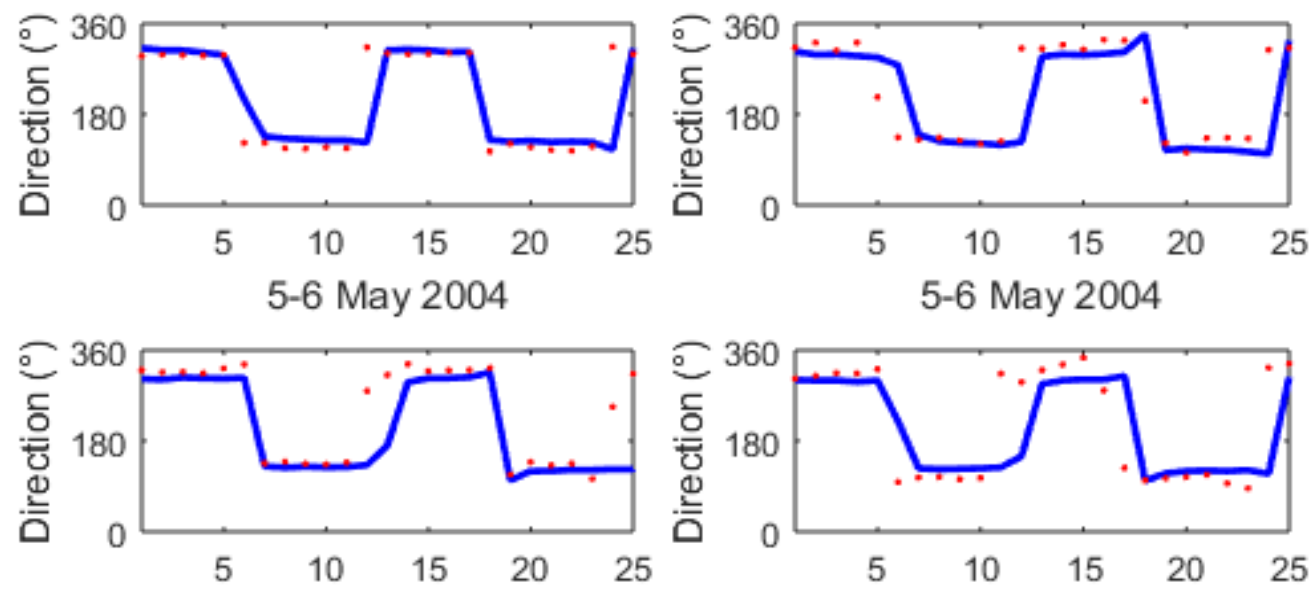

5-6 May 2004
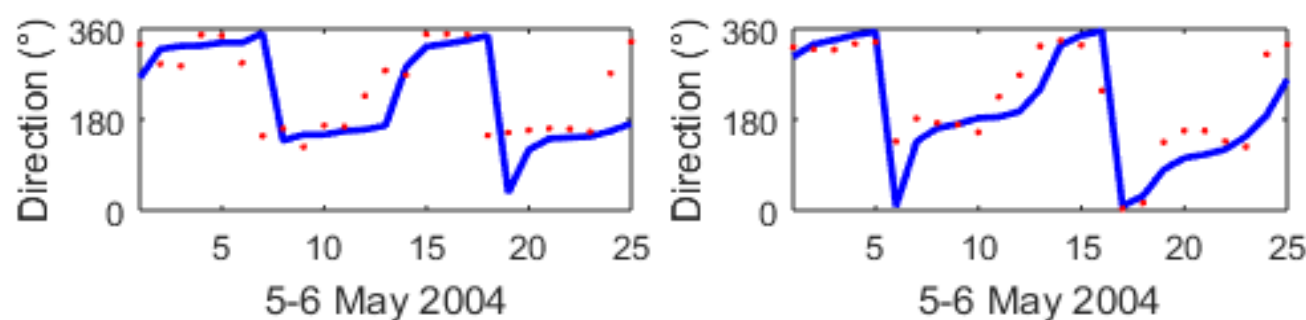

Figure 4b. Comparison of observation tidal current direction (red dot) and simulation result (blue line) 


\section{Tidal current characteristics}

Figure 6 shows the flow field diagram from May 5 to 6, 2004. Overall, the results calculated by the model basically reflect the state of the measured flow rate. The tide of studying the sea area is a regular semidiurnal tide. The tidal waves entering the Bohai Sea are affected by the semi-closed bay form, forming complex rotating tidal waves. During the flood tide, the direction of the tidal current moves from north to south, forming a large clockwise vortex in the east and south sea areas of the old Yellow River estuary and then flowing to the western and central sea areas of Laizhou Bay. During the ebbtide, the sea in the southern part of the old Yellow River estuary (west of Laizhou Bay) was rotated counterclockwise and transported northward. The study of the ebbtide of the sea area lasts longer than the flood tide, and the average flow rate of the ebb tide is greater than the average flow rate of the flood trend, showing an imbalance of fluctuations in the current flow.
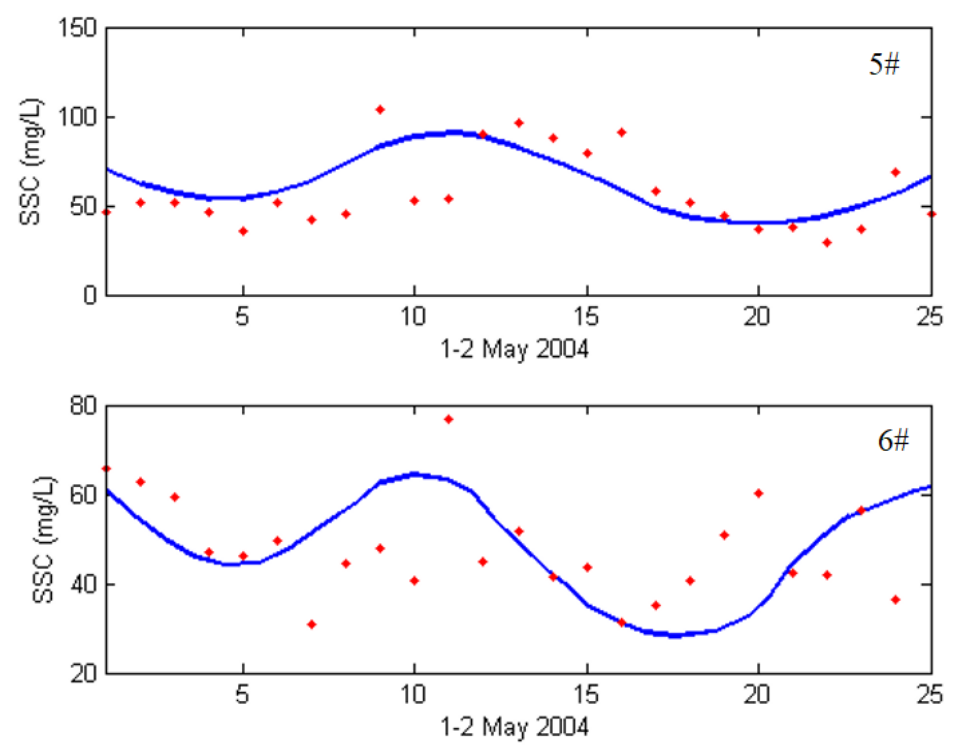

Figure 5. Comparison of observation sediment concentration (red dot) and simulation result (blue line)

Table 2. The mean absolute error of simulation and observation

\begin{tabular}{c|c|c|c|c}
\hline & & & & \\
\hline T & 0.11 & - & - & - \\
$1 \#$ & - & 0.13 & 10.9 & - \\
$2 \#$ & - & 0.09 & 14.8 & - \\
$3 \#$ & - & 0.24 & 13.9 & - \\
$4 \#$ & - & 0.20 & 19.0 & 14.9 \\
$5 \#$ & - & 0.11 & 22.1 & 11.0 \\
$6 \#$ & - & 0.07 & 20.1 & \\
\hline
\end{tabular}

Figure 7 shows the maximum flow velocity distribution of the study sea area in a full tide in May 2004. The contour of the northern Yellow River estuary is basically parallel to the shoreline. The flow velocity is from $0.5 \mathrm{~m} / \mathrm{s}$ increased to $1 \mathrm{~m} / \mathrm{s}$ in the $2-15 \mathrm{~m}$ isobath. In the southeast direction of the old Yellow River estuary, the maximum flow velocity 
increases rapidly from $0.5 \mathrm{~m} / \mathrm{s}$, forming a high value zone with a maximum flow velocity of $1.4 \mathrm{~m} / \mathrm{s}$. According to historical data, there are two large flow velocity areas in the Yellow River estuary, one of which is in the southeast of Laohekou. The maximum possible flow velocity is $1.8 \mathrm{~m} / \mathrm{s}$.
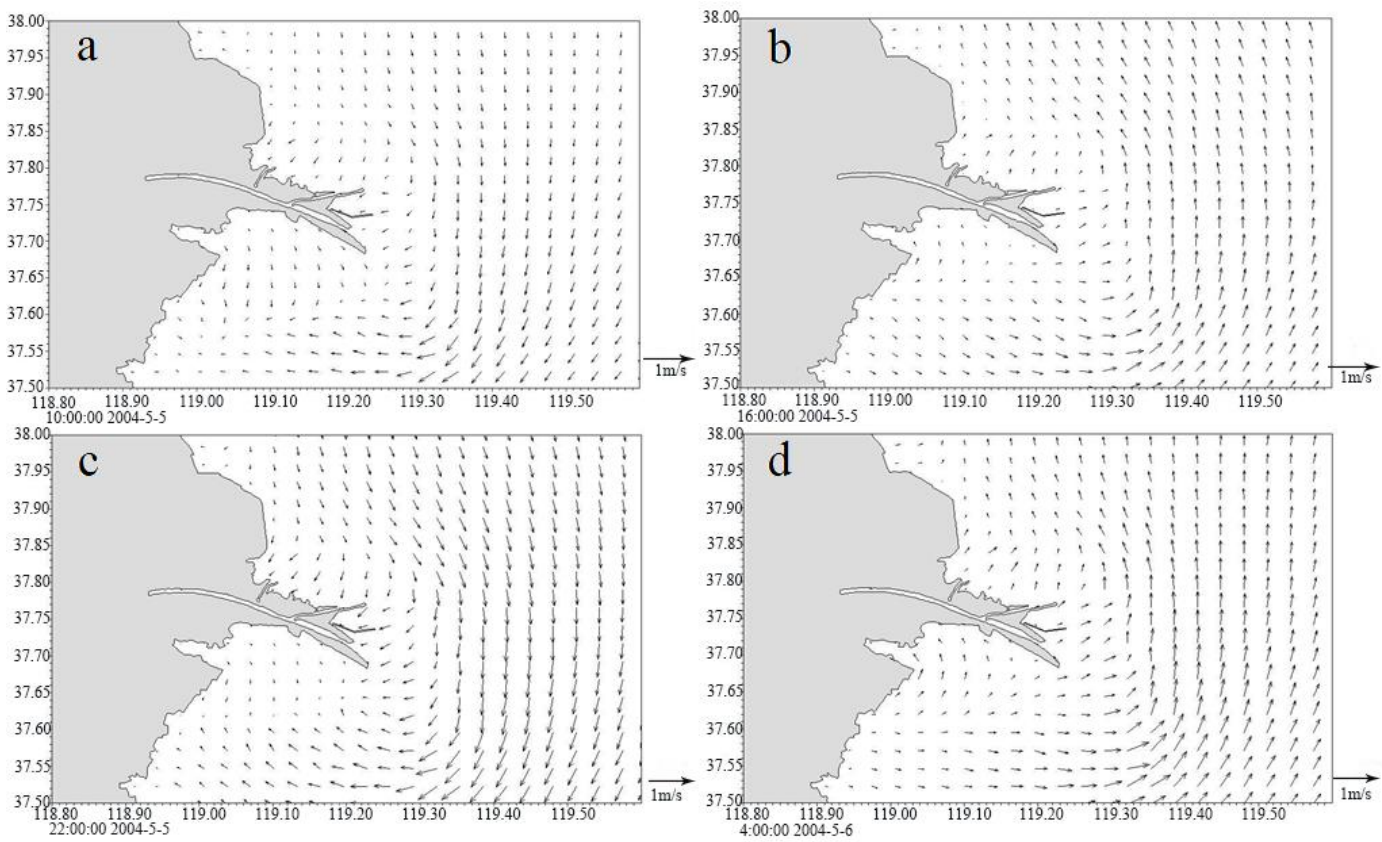

Figure 6. Distribution of tidal current during 10:00 5th - 4:00 6th May 2004

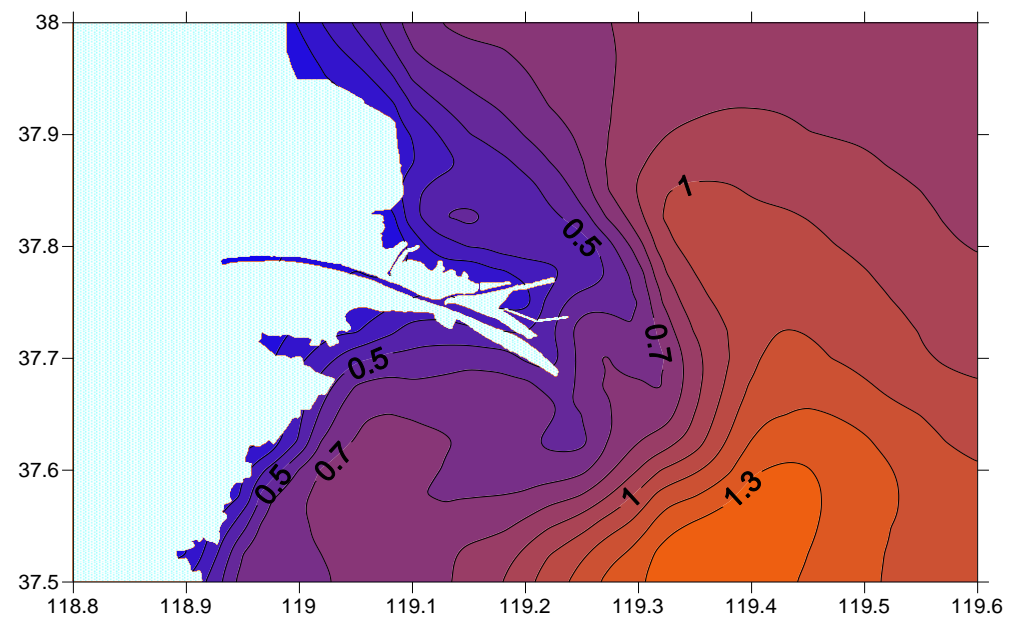

Figure 7. Maximum velocity distribution $(\mathrm{m} / \mathrm{s})$ of the study sea area

\section{Sediment movement influenced by tidal current}

Under the influence of no waves, sediment movement is mainly affected by the trend. The numerical simulation of suspended load concentration and sedimentation and siltation in the absence of wind is shown in Figure 8. The northern part of the sea is affected by sediment from the Yellow River and is weakly silted. The concentration of 
suspended load is generally $0.6 \mathrm{~kg} / \mathrm{m} 3$, and the southern part is scouring. In the strong tidal zone in the southeast of the old Yellow River estuary, the scouring is the strongest.

Without considering the influence of waves, the stability of the particles is actually mainly controlled by the water pressure of the film and the adhesion between the particles and the performance of gravity is not dominant. From this point of view, in the absence of waves, the finer the sediment particles, the more difficult it is to reach the conditions of suspension. It can be seen that the effect of waves on the sediment, especially the fine sediment, is more obvious. The waves in the Yellow River estuary are basically wind and waves. Although the average wave energy intensity is not large, due to the fine sediment of the Yellow River underwater delta, the levitation force of the waves on the seabed sediment is relatively large.

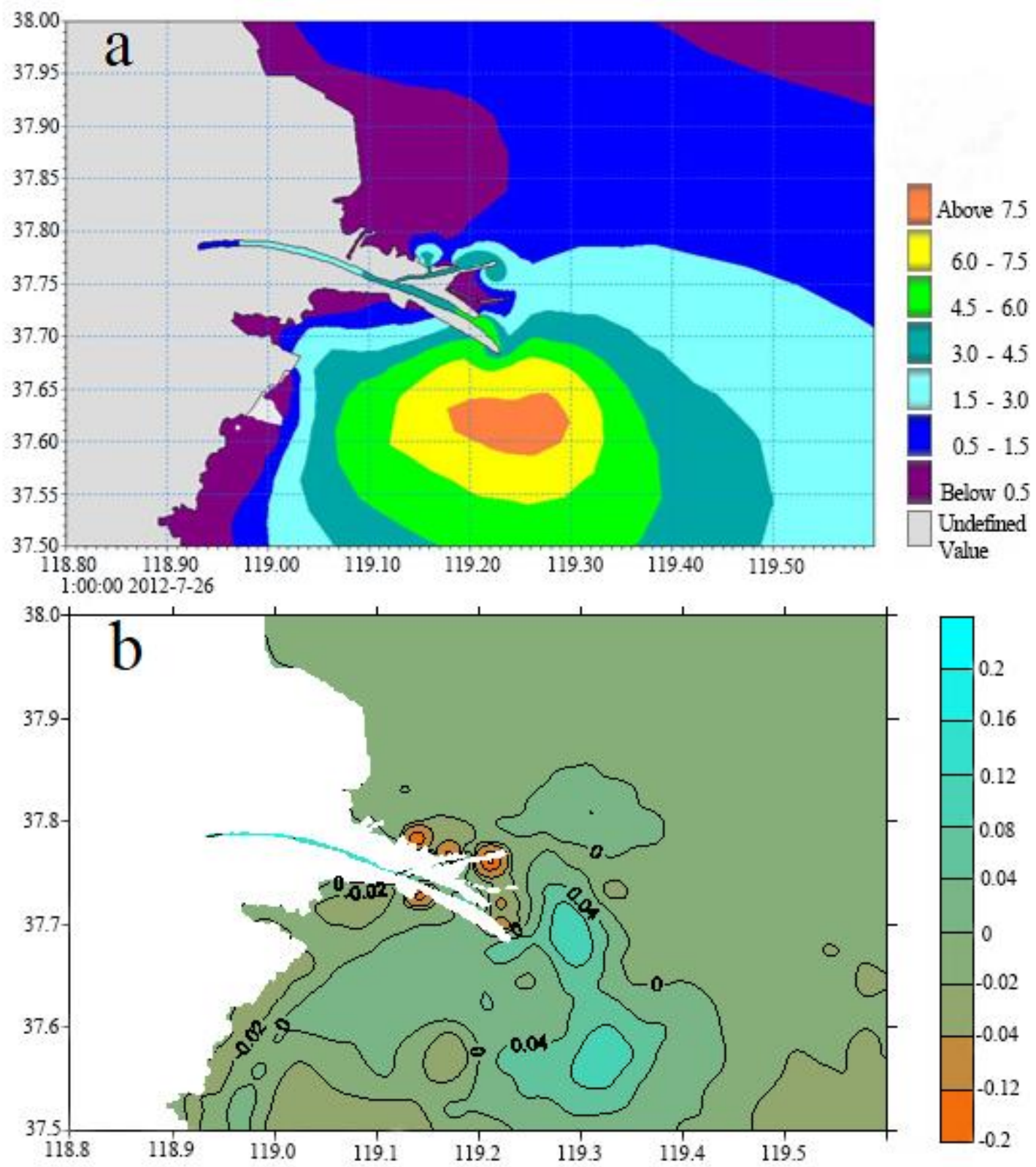

Figure 8. Distribution of suspended load concentration (a) and distribution of scouring and silting under no-wave action (b, unit: $m$, positive value is scouring) 


\section{Discussion}

Zhang (2011) examined coastline changes in the Modern Yellow River delta in China on the basis of remote sensing and GIS techniques, the Landsat data obtained in 1987, 1996, and 2008. Peng et al. (2010) found that the water discharge and sediment load into the sea were decreasing from 1950 to 2007 with serious fluctuation at Lijin. Cui et al. (2011) extract mean high tide lines of the Yellow River estuary from 1976 to 2005, and explored relationships between the accretion-erosion of land and the runoff and sediment load of the Yellow River. Li et al. (2010) diagnosed the effects of different hydrodynamic factors on the transport of suspended sediment discharged from the Yellow River in the Bohai Sea. Peng et al. (2013) analyzed temporal and spatial evolution of coastline and subaqueous geomorphology in muddy coast of the Yellow River Delta based on measured data of coastline and bathometry.

The coast near the Yellow River estuary is mucky, and the sediment movement is generally dominated by the suspended load. The waves cause the sediment to enter a suspended state, and even if the suspended load is superimposed with the velocity of the smaller water, a large amount of sediment transport will occur. Studies have shown that, without considering the influence of waves, the stability of particles is actually mainly controlled by the water pressure of the film and the adhesion between particles, and the performance of gravity is not dominant. From this point of view, in the absence of waves, the finer the sediment particles, the more difficult it is to reach the conditions of suspension. It can be seen that the effect of waves on the sediment, especially the fine sediment, is more obvious. The waves in the Yellow River estuary are basically wind and waves. Although the average wave energy intensity is not large, due to the fine sediment of the Yellow River underwater delta, the levitation force of the waves on the seabed sediment is relatively large.

\section{Impact of north wave}

The north wind in the research area is the strongest, the north wind is the least in summer and the most in spring, autumn, and winter. The average wind speed is $12.3 \mathrm{~m} / \mathrm{s}$, and it is stronger at sea. In the cold wave wind on March 3-5, 2007, the average wind speed at sea reached 9-10, and the extreme wind speed is $21.5 \mathrm{~m} / \mathrm{s}$. Therefore, in this compromise, the wind speed of the north wind is designed to be $18 \mathrm{~m} / \mathrm{s}$ and the direction is straight north.

In the process of northbound wind, $2.3 \mathrm{~m}$ waves can be formed in the sea near the Yellow River estuary, and the suspended sediment concentration reaches $13 \mathrm{~kg} / \mathrm{m}^{3}, 20$ times higher than that in the case of no waves. Under the influence of northbound waves, the east sea area of Laohekou river presents scour on the whole. There are two high value centers in the northeast and southeast, and the maximum net scour value is up to $1.8 \mathrm{~m}$. Inshore waves are small, and the sand-lifting capacity of waves is weak, showing weak deposition of about $0.2 \mathrm{~m}$. The wave action in the new and old Yellow River estuary is mainly reflected by erosion. Erosion in the old Yellow River estuary is caused by both waves and currents.

The distribution of wave field under the action of northbound wind, the distribution of suspended sediment concentration under northbound wave action, the distribution of erosion and deposition under the influence of north waves and the change of scour and silt caused by the north wind waves are shown in Figure 9. 

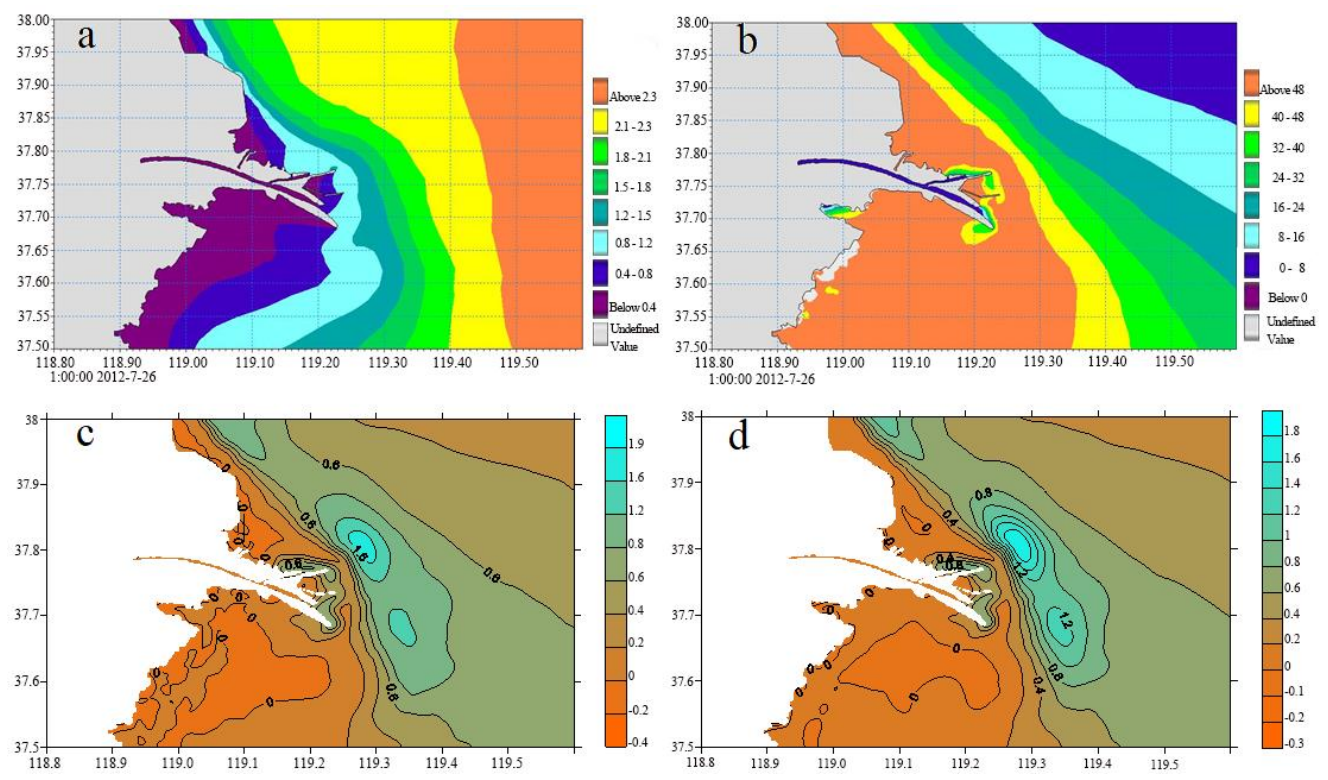

Figure 9. a Distribution of wave field under the action of northbound wind (significant wave height, $m), b$ Distribution of suspended sediment concentration under northbound wave action, $c$ The distribution of erosion and deposition under the influence of north waves ( $m$, positive for scour) $d$ The change of scour and silt caused by the north wind waves ( $m$, positive for scour)

\section{Impact of east wave}

Under the influence of monsoon climate, the sea area is mainly dominated by south wind and north wind, and the direction is mostly east, forming southeast wind or northeast wind. In a year, 17 out of 33 north wind processes occur in the form of northeast wind, and the average wind is between north wind and south wind. At 21 o 'clock on October 11, 2003, affected by the typhoon, the wind speed of easterly wind increased to $20 \mathrm{~m} / \mathrm{s}$ and then slowly decreased, and the extreme value is smaller than the maximum value of northerly wind. Therefore, the wind speed of easterly wind is designed to be $15 \mathrm{~m} / \mathrm{s}$.

The east wind formed a wave of $2 \mathrm{~m}$ in the research area, and the suspended sediment concentration at the depth of $10 \mathrm{~m}$ reached $10 \mathrm{~kg} / \mathrm{m}^{3}$, which is 16 times the concentration without waves. The distribution of net scour and silt under the influence of eastbound waves is similar to that of northbound waves, but the scour zone located in the east of the estuary has a smaller scope and intensity, and the net wave erosion depth is $1.7 \mathrm{~m}$, while the direction of scour zone also changes to north-south direction.

The distribution of wave field under the action of eastbound wind, the distribution of suspended sediment concentration under eastbound wave action, the distribution of erosion and deposition under the influence of east waves and the change of scour and silt caused by the east wind waves are shown in Figure 10.

\section{Impact of south wave}

In the process of the south wind, sea and land breeze wind speed difference is small, the mouth observed port south winds only 3 times a year, with an average of $11.6 \mathrm{~m} / \mathrm{s}$, maximum value is $15.6 \mathrm{~m} / \mathrm{s}$, appeared in the July 29, 2006, considering the south wind frequency is low, the aerodynamic probability is less, so take the average wind speed for reference, the design wind speed $11.6 \mathrm{~m} / \mathrm{s}$, and set this direction due south. 
The south wind process can generate $1 \mathrm{~m}$ waves, and the suspended sediment concentration at $10 \mathrm{~m}$ reaches $2.7 \mathrm{~kg} / \mathrm{m}^{3}$, which is four times larger than the suspended sediment concentration under no wind condition. Compared with northbound and eastbound waves, southbound waves have weak erosion capacity, with maximum erosion thickness of less than $1 \mathrm{~m}$.

The distribution of wave field under the action of southbound wind, the distribution of suspended sediment concentration under southbound wave action, the distribution of erosion and deposition under the influence of south waves and the change of scour and silt caused by the south wind waves are shown in Figure 11.

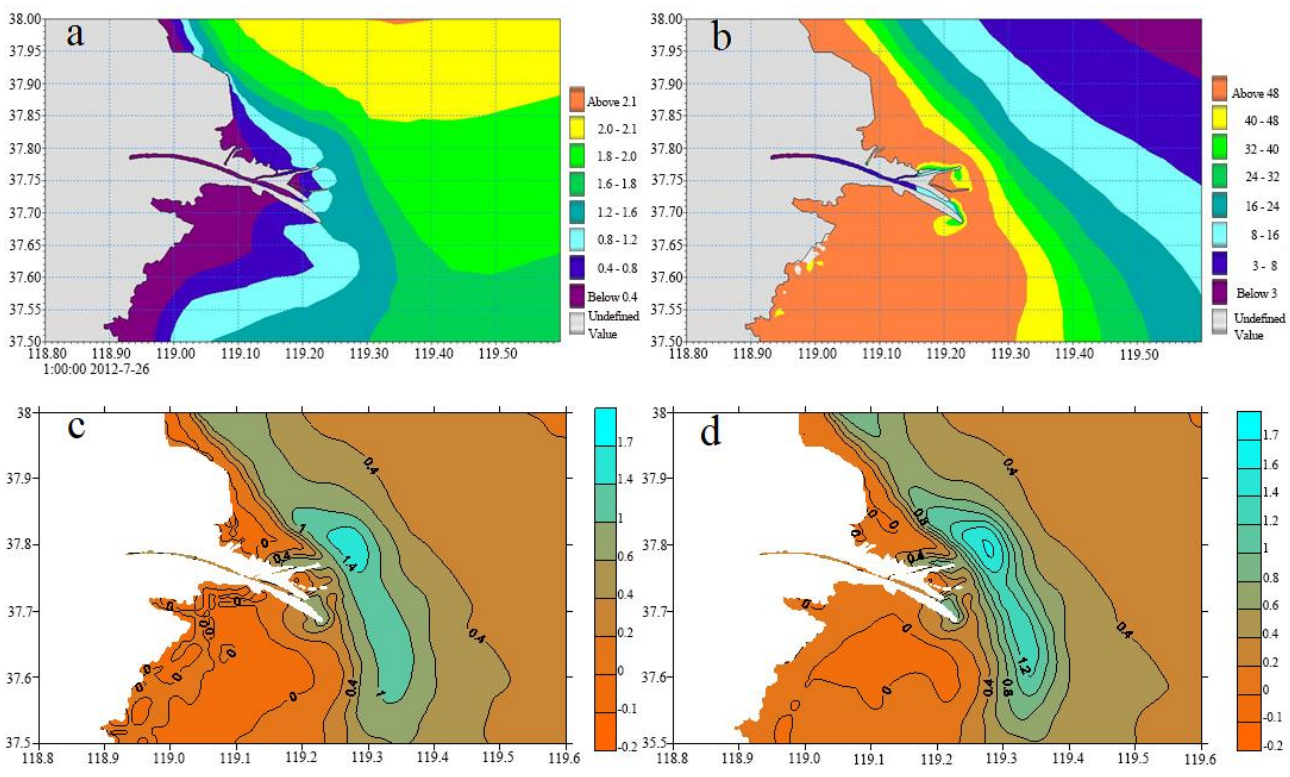

Figure 10. Same like Fig. 9 but under east wave conditions
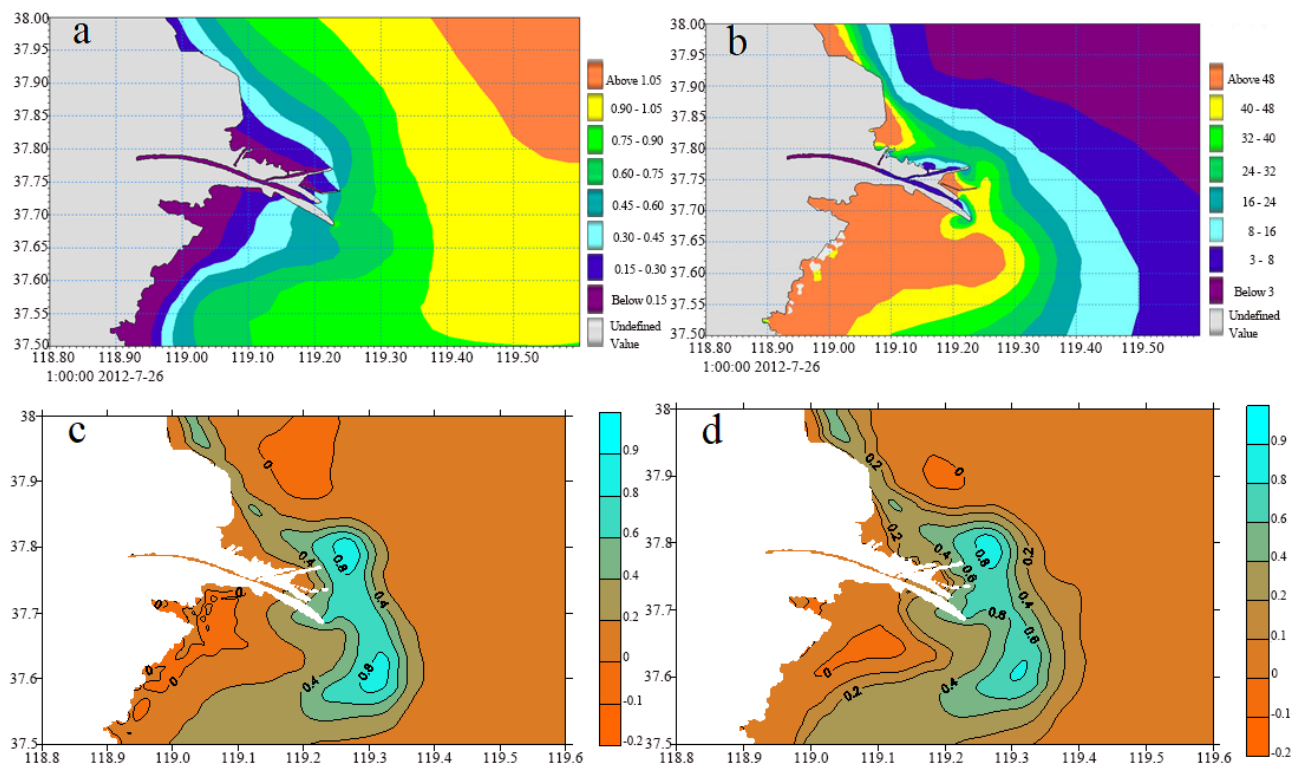

Figure 11. Same like Fig. 9 but under south wave conditions 


\section{Conclusion}

Sediment movement is influenced by runoff, tide, wave, sediment particle size, cumulative siltation area and the specific gravity and composition of the sediment. Wave is an important dynamic factor in the process of erosion and deposition of sediment, which plays an important role in the transport of river sediment into the sea, the re-suspension of seabed sediment and the formation of delta coast.

The suspended sediment concentration in the wave action is much higher than the concentration of the tidal current. The sediment concentration is 20,16 and 4 times of that without wind wave under north, east and south wind condition respectively. The resuspension is strongest under north wind condition and weakest under south wind condition. The erosion is very strong at the north side slope of Yellow River influenced by north and east waves, and the erosion is relative weak at the south side.

The erosion of the shallow sea floor by waves is very obvious. Wind and waves cause strong scour zone to the east of the estuary. Under the condition of northbound waves, the scour zone is distributed in SE-NW direction, with the maximum scour thickness of $1.9 \mathrm{~m}$. Under easterly wave condition, the scour range is more intense, and the scour zone shows a north-south trend, with the maximum scour thickness up to $1.7 \mathrm{~m}$. The scour and silting action of southward wave is weak.

Acknowledgements. This work is financially supported by the National Key R\&D Program of China (2018YFB0504904), National Natural Science Foundation of China (51779236) and Open Fund of Shandong Province Key Laboratory of Ocean Engineering.

\section{REFERENCES}

[1] Cui, B. L., Li, X. Y. (2011): Coastline change of the yellow river estuary and its response to the sediment and runoff (1976-2005). - Geomorphology 127(1-2): 0-40.

[2] Fan Hui, Haijiun, H. (2005): Changes in huanghe (yellow) river estuary since artificial rerouting in 1996. - Chinese Journal of Oceanology and Limnology 23(3): 299-305.

[3] Huang, S., Yin, X., Zhao, X. (2018): The effects of saltwater intrusion on suspended sediment movement in estuary. - IOP Conference Series: Earth and Environmental Science 121: 052012.

[4] Kong, Q. R., Jiang, C. B., Qin, J. J., Guo, B. (2009): Sediment transportation and bed morphology reshaping in yellow river delta. - Science in China 52(11): 3382-3390.

[5] Li, A., Li, G. X., Cao, L. H., Zhang, Q. D., Deng, S. G. (2004): The coastal erosion and evolution of the yellow river delta abandoned lobe. - Journal of Geographical Sciences 14(4): 465-472.

[6] Li, G., Xue, X., Liu, Y., Wang, H., Liao, H. (2010): Diagnostic experiments for transport mechanisms of suspended sediment discharged from the yellow river in the bohai sea. Journal of Geographical Sciences 20(1): 49-63.

[7] Liu, F., Chen, S., Peng, J., Chen, G. (2011): Temporal variability of water discharge and sediment load of the yellow river into the sea during 1950-2008. - Journal of Geographical Sciences 21(6): 1047-1061.

[8] Liu, X., Liu, J., Feng, X. (2018): Inversion and Prediction of Consolidation Settlement Characteristics of the Fluvial Sediments Based on Void Ratio Variation in the Northern Modern Yellow River Subaqueous Delta, China. - Oceanic and Coastal Sea Research 17(3): 545-554. 
[9] Peng, J., Chen, S. L. (2010): Response of delta sedimentary system to variation of water and sediment in the Yellow River over past six decades. - Journal of Geographical Sciences 20(04): 613-627.

[10] Peng, J., Ma, S., Chen, H., Li, Z. (2013): Temporal and spatial evolution of coastline and subaqueous geomorphology in muddy coast of the yellow river delta. - Journal of Geographical Sciences 23(3): 490-502.

[11] Peng, Y., Su, M., Wang, Z. B., van Rijn, L. C., Zhang, C. K., Stive, M. J. F. (2018): Modelling tidal-induced sediment transport in a sand-silt mixed environment from days to years: Application to the Jiangsu coastal water, China. - Coastal Engineering 141: 86-106.

[12] Wang, N., Li, G. X., Xu, J. S., Qiao, L., Dada, O. A., Zhou, C. (2005): The Marine Dynamics and Changing Trend off the Modern Yellow River Mouth. - Journal of Ocean University of China 14(03): 433-445.

[13] Wang, K. F. (2019): Evolution of yellow river delta coastline based on remote sensing from 1976 to 2014, China. - Chinese Geographical Science 29(02): 3-13.

[14] Wang, N., Qiao, L., Li, G., Zhong, Y., Song, D., Ding, D., Gao, F., Ji, F. Y. (2019): Numerical study on seasonal transportation of the suspended sediments in the modern yellow river mouth effected by the artificial water and sediment regulation. - Journal of Ocean University of China 18(1): 20-30.

[15] Xu, J. X. (2003): Sediment flux to the sea as influenced by changing human activities and precipitation: example of the yellow river, China. - Environmental Management 31(3): 0328-0341.

[16] Yang, H. B., Li, E. C., Zhao, Y., Liang, Q. H. (2017): Effect of water-sediment regulation and its impact on coastline and suspended sediment concentration in yellow river estuary. - Water Science and Engineering S1674237017301084.

[17] Zhan, C., Yu, J. B., Wang, Q., Li, Y. Z., Zhou, D., Xing, Q. H., Chu, X. J. (2017): Remote Sensing Retrieval of Surface Suspended Sediment Concentration in the Yellow River Estuary. - Chinese Geographical Science 27(06): 934-947.

[18] Zhang, Y. (2011): Coastal environmental monitoring using remotely sensed data and GIS techniques in the modern yellow river delta, China. - Environmental Monitoring \& Assessment 179(1-4): 15-29. 